\title{
The Thinking about the Biochemistry Teaching in Food Quality and Safety Specialty
}

\author{
Ling Li \\ College of Food Science and Biotechnology \\ Tianjin Agricultural University \\ Tianjin, China \\ liling19820925@163.com \\ Juanjuan Bai \\ College of Food Science and Biotechnology \\ Tianjin Agricultural University \\ Tianjin, China \\ 1160478383@qq.com
}

\author{
Yani Chang \\ College of Food Science and Biotechnology \\ Tianjin Agricultural University \\ Tianjin, China \\ 1716165629@qq.com \\ Tieling Liu* \\ College of Food Science and Biotechnology \\ Tianjin Agricultural University \\ Tianjin, China \\ ltl@tjau.edu.cn \\ *To whom correspondence should be addressed.
}

\begin{abstract}
As a professional profession, the greatest characteristic of teachers is the diversification of professional roles. The identity of teaching researchers requires teachers to treat teaching tasks with the attitude of change and development, and constantly improve teaching methods. During the teaching of speciality biochemistry of food quality and safety, the writers found that the problems existed in the course; the teaching methods and experimental teaching which were in need of innovation, the overall teaching system also need be improved in order to promote the realization of all-round quality education.
\end{abstract}

Keywords-biochemistry; teaching method; experimental operation; food quality and safety specialty

\section{INTRODUCTION}

With social progress and education reforms, teaching scientific and cultural knowledge no longer be considered the goal of talent cultivation for higher education, but for training talented citizens for society. It is no longer confined to teaching . It requires comprehensive development and training comprehensive talents. The realization of educational goals generally requires the construction of courses, curriculum which was the basis for teachers' teaching and students' learning, the quality of curriculum directly determines the quality of talent training. Biochemistry which as a basic course, was a compulsory course for many institutions of higher learning, the structure and function of protein-based biomolecules, as well as sugar metabolism, lipid metabolism and amino acid metabolism be included in this curriculum, the basic principles of biochemistry were also systematically expounded in this curriculum. The goal of training students in food quality and safety specialty is mainly in the field of food nutrition, health, safety detection and supervision. Students should learn not only theoretical knowledge of physiology and biochemistry, but the ability of practical operation. However, the teaching content of biochemistry is relatively dull and abstract, which could make students feel weary of learning.
Reform and innovation with purpose and direction for the content of the curriculum which needed to carry out in order to improve students' interest in learning and adapt to the needs of society's for comprehensive talents.

\section{THE EXISTING PROBLEMS OF THE COURSE}

The first step to solve the problem is to discover the problem. In the teaching process, through the observation of students' classroom performance, the analysis of students' score, and the evaluation of experimental operations, the author finds that the existing problems are mainly the poor adaptability of students' learning methods and the lack of initiative in the classroom and passive practice.

\section{A. Poor adaptability of learning methods}

After entering the university, students face the problem are that they cannot change their learning methods generally. They continue to follow the high school learning methods so that they are accustomed to accepting the content taught passively by teachers and ignore the importance of participation. Furthermore, they spend all time in memorizing knowledge points, taking notes, and dealing with exam questions in order to pass the written test. However, there is a big difference between the university curriculum and the high school curriculum. the university curriculum always place emphasis on self-study whose the major teaching objectives are more to cultivate students' study habits and learning methods, In addition to imparting basic knowledge. In addition, there are many subjects in the university curriculum and there are limited schedules for each subject. Therefore, teachers will try to cover all important knowledge points within a limited period of time. This will cause many students who just went to university to not catch up with the teachers. They cannot adapt to the fast pace lecture style. Students generally report that class is too fast. Often the content of the previous knowledge point has not yet been understood, it has 
already reached the next part of the content, and the following content is linked to the above content, so they have a vicious circle, and finally they fall into confusion, so there is not much to understand in one lesson. Even if some students do not understand it, they will not listen directly and deal with it negatively. In terms of life, students have more time for selfreliance than higher ones. They spend most of their time and energy on more active activities such as clubs and do not coordinate their studies and life very well, classes are often absent-minded, and there is very little time spent learning after class.

\section{B. Lack of initiative in class}

In the classroom, both teachers and students are masters. However, based on traditional teaching methods and study habits, teachers are used as the protagonist of the classroom in the hearts of students. They passively listen to teachers and lack the awareness of independent thinking. There are three main types of student performance in the classroom. One type of student lacks a sense of learning. He or she rarely interacts with the teacher. It completely handles the classroom and is extremely uninterested in the content of the classroom. Another class of students is still like high school, the class process is only the mechanical transfer of teacher explanations to their own notebooks. For fast-paced classes, they are generally 'busy". The teacher's PPT is replaced quickly, and they will pay much attention on the rush to copy PPT, so there is no time to think and participating in the classroom. They seemingly very serious, but for questions in the classroom, their answer is often unsatisfactory. In the end, only a small group of students will be diligent in their brains, diligent in thinking, and follow their teachers in the process of teacher explanations. They will raise doubt timely. Such students often learn very easily. They jump out of the inertia of learning, and are the masters of their own learning [1].

\section{Experimental operation is more passive and lacks practical awareness}

At present, the teaching of biochemistry experiments in higher education is mainly the "cramming" model. Teachers generally follow the principle of experimenting first, followed by specific experimental procedures, and finally present experimental matters needing attention. The student's experiment process is based on the teacher's explanation of the steps to complete the operation of the machine. Although this teaching mode is a practical lesson, it is actually a process that students passively accept. Students often only pay attention to the theoretical part, and the operation process is only reproduced in accordance with the teacher's process. The principle and design ideas of the experimental design process are not deeply considered. As for the various possibilities that appear in the experiment, they are not aggressively conjecture and lack of agility. In addition, the preliminary preparation process of the experiment is prepared by the experimental teacher in advance, and the students have little understanding of the basic work such as reagent preparation. Since the vast majority of experiments are proof experiments, the results of the experiments are already known by the students, so most students are not interested in the experiments. For experiments that require group operations, students shirk responsibility and lack hands-on awareness [2].

\section{Teaching Method ReForm And InNOvation}

Both teachers and students are the main body of the teaching process, teachers are the organizers of the courses, and students are learners in the classroom. Teachers play a leading role, need not only actively communicate with students, understand students' real ideas, find difficulties in the students' learning process, but also make targeted changes according to issues, adjust and innovate teaching methods, and make students relaxed master the teaching content, and master more learning skills, practical skills, and thinking skills in the learning process to meet social requirements. In the process of biochemistry teaching, the author discovered through exploration that the innovation of teaching methods can be carried out from the following points.

\section{A. Grabbing from the first class and grasping from the introduction}

The first lesson of each subject is usually an introductory class. The content of the introductory part is to let students have a clear understanding of the entire knowledge system of the course, and more importantly, it is able to initiate and stimulate students' interest in learning. Good teachers will make full use of the introduction. From the first class, they will arouse students' curiosity and learning expectations. The biochemistry course is monotonous and boring according to the student's inertial thinking, and the course content itself is numerous and complicated. The students often retreat without fighting and there is already a fear before of class, so teachers should focus on cultivating students' interest and confidence in learning from the very beginning. The introduction part is not obscure, so teachers can use a relatively easy and lively teaching method. They can use the video related to this course to give students the "opening remark", however video content should be easy and lively to avoid regular instructional videos. When the video attracts students, you can strike while the iron is hot, transfer content to this course. When introducing the content of the course to students, it must be clearly structured and try to divide the book knowledge into several categories. The contents of biochemistry textbooks are many and the books are very thick. This will reduce students' visual and psychological concerns to a certain extent. When describing each type of content in detail, it is possible to begin discussions with students in conjunction with the biological phenomena that students are interested, such as female students are most concerned about how to lose weight. In particular, food quality and safety professional can also be related to related professional content such as the identification of adulterated milk and the topics such as good or bad that breakfast shop use repeatedly used oil to frying fritters brought the students into the chapters, and provided motivation for follow-up study. Finally, the impression given to the students in the first lesson of the teacher is likely to accompany the student's entire learning process. Therefore, it is necessary to grasp the teaching emotions and not to be too strict, so that the students will have a school dropout mentality, and they also should not be too loose to avoid the students' slackening, they should give 
full play to one's own personal teaching charm and improve students' interest and motivation in learning [3].

\section{B. Using heuristic teaching}

Heuristic teaching differs from traditional teaching methods. This method focuses more on the guiding role of teachers, teachers are required not to explain everything in the course, they can use conversational methods, discussion methods, and other inclusive teaching methods to guide students to think and find answers for themselves. In order to promote students' initiative thinking, different rewards can also be set based on answering questions in class. Encourage students to learn by themselves, even for better students, can let them act as "little teachers" to explain to other students. In addition, the group discussion is also a better way of learning. Teachers can assign tasks to the teams according to the contents of the class. The team members work together to solve the problems, and then teach to other students. According to the performance of each group, they are ranked and the corresponding rewards are obtained. Heuristic teaching is also an effective means to cultivate student's learning confidence. By solving problems by themselves, students can not only gain the joy of success, but also establish the confidence of learning, laying the foundation for future study work.

\section{Flexible choice of teaching tools}

With the advent of the era of electronic information, various kinds of convenience products have emerged in an endless stream. Nowadays, writing on the blackboard have been replaced by multimedia, multimedia teaching is more convenient, teachers can save class time, and tools such as video and animation and pictures can be used to visualization abstract and complex knowledge, easy for students to understand and remember. However, there are also many problems in multimedia teaching. Usually, teachers make the course content into courseware, and the amount of courseware information is large, so the speed of the teacher's turning PPT and the lectures are unconsciously accelerated. Thus, students often have no time to understand and remember, and there is no writing on the blackboard, they can't study on their own, so they forget immediately after learning. In addition, multimedia teaching is also easy for teachers to become inert. They only teach PPT content and rarely use blackboard to supplement relevant knowledge for students.

For the convenience of student learning, teachers should be flexible in the choice of teaching methods. According to the characteristics of the teaching content, the combination of blackboard and multimedia is used. For abstract and difficult to understand knowledge, multimedia can be fully utilized and the abstract knowledge can be visualized. For scattered knowledge, we can write on the blackboard to help students remember at any time. The blackboard can also clearly list the main lines of knowledge in this class, allowing students to learn in an organized manner and connect the knowledge together to make students easier to remember and understand. In addition to common teaching methods, you can also boldly try to innovate the teaching methods, inspire students' interest in learning, and improve their overall quality [4].

\section{For some teaching content, use the micro-course teaching method}

With the micro-course teaching method, teachers must first select the teaching content and choose the part that fits the teaching method. It can not be generalized, but it will affect student learning. Secondly, teachers are required to complete their own network information and teaching resources, and content should be rich and comprehensive. Students are allowed to independently study through the network in advance, and they can also use online to test their own learning outcomes and targeted supplementary learning content. Teachers can assist students in learning and provide guidance on difficult topics. The teaching tool of the microcourse teaching method is diversified. Teachers can make full use of the WeChat public platform, allow students to interact and communicate, and publish the expanded teaching resources on the public number and campus public network, providing reference materials for students to consolidate their after-school knowledge [5].

\section{E. Use the necessary "tough" measures}

In the teaching process, students are the main body, teachers are the guides, and all educational activities are based on the students' autonomy. Students are allowed to learn spontaneously. Teachers cannot force students, especially college students, they are more free people and can fully exert their abilities and passion. But precisely because high school is depressed for too long, for them, freedom is sometimes the biggest obstacle to learning. Some students attend classes only on the basis of interest. The courses they are interested in are active and serious. They do not pay attention to the courses they are not interested in and even skip class. Therefore, in addition to improving teaching methods and improving the attractiveness of the curriculum to students, teachers must also take appropriate "tough" measures to urge students to learn basic courses. Teachers can ask more questions in class and interact more with students, random questions can keep students alert and concentrated. In particular, before and after each class, the content of the question may be directed to the content of the previous class and the contents of the class or even the next class in order to promote the student's after-class review and pre-class study. Assignment homework should reflect differences and reduce the standard of answering the questions. Each student should make a difference in their assignments, so that students can think and solve problems on their own, avoid plagiarism, and the quality of the homework assignments is directly recorded in the final assessment.

\section{CHANGE IN PRACTICE TEACHING}

\section{A. Clear experimental tasks and assessment methods}

The biochemistry course is a comprehensive course combining theory with practice. It is generally based on theory, and part of experimental teaching is not valued by students. Due to the limited time and conditions, the experimental courses were conducted in small groups. The overall participation of students is not high, and the two levels of differentiation are serious. The active, strong hands-on ability students in the group dominate, and students who are not 
interested in the experiment evade experimentation and rely on other team members. In order to allow all students to participate in the experiment, all students have practical opportunities. Teacher can arrange as many personal experiments as possible according to the contents of the experiment. If need team to conduct experiment, teacher should also reduce the number of group members as much as possible, and require students to strictly divide the work. Each person has an experimental task. Finally, according to the completion of the experiment, to comprehensively evaluate the performance of students and enhance students' ability to operate.

The general performance assessment of experimental courses is mainly based on experimental reports, which is relatively single, and the credibility is not high. Teachers can improve experimental assessment methods to improve the fairness of the score, and also urge students to seriously experiment [6]. Experimental assessment should increase the proportion of normal performance, and give points according to the specific experimental operation of students. The preview report must have predictions about the experiment. The experiment report requires students to think about the causes and principles of the analysis of experimental phenomena. Finally, according to the comprehensive score, the performance of the experiment was graded.

\section{B. Strengthen the operation of design type experiments}

Experiments are an important part of teaching. At this stage, the main purpose of experimentation is to demonstrate the known experimental results, standardize the operation process, and have similar experimental results. This is not easy to stimulate the students' experimental interest, and the structure of the experimental arrangement is too single, the connection between the experiment and the experiment is not close enough, and the coherence is not enough, which is not conducive to the students' complete grasp of theoretical knowledge [7]. Therefore, in practice teaching, we can strengthen the development of design type experiments, let students design their own experimental programs, summarize experimental procedures, find out the reasons for successes and failures through experimental operations, and reflect on experimental contents. This will not only help improve students' practical ability, can also exercise the ability of students to think independently and solve problems.

\section{CONCLUSION}

In order to implement a comprehensive quality education and achieve a lifelong sustainable development of students, teachers are the leading players in teaching, apart from imparting scientific and cultural knowledge, they are more likely to reflect on and discuss with and become researchers in education, provide better knowledge services for students and cultivate high-quality talents for the society. In the teaching process of the biochemistry course, the author discovered the students' existing problems, reviewed and summed them, and finally made specific adjustments from the reform of the teaching methods and the improvement of experimental teaching. The purpose was to improve the overall quality of the students and to lay a solid foundation for their future study and work.

\section{ACKNOWLEDGMENT}

This work was supported by grants from the Tianjin Agricultural University Education Teaching Reform Research Project (No. 2016-B-07), the Tianjin Agricultural University Teacher Education Reform and Innovation Guide Development Project (No. 20170412), the Research Project of Undergraduate Teaching Quality and Reform of University in Tianjin (No. 171006103C), and the Food Quality and Safety Teaching Team of Tianjin.

\section{REFERENCES}

[1] L. Yuan, M.Y. Yuan, Z.Y. Gan, C. Li, and R.C. Gao, "A discussion on how to learn to biochemistry for food specialty," Farm Products Processing, vol. 23, pp. 74-75, December 2017. (In Chinese)

[2] X.S. Yang, W.G. Zeng, and Z.M. Li, "Study on the teaching reform of biochemistry experiment in biology and food specialty-a case study of bengbu university," Journal of Chifeng University(Natural Science Edition), vol.31, pp. 224-225, January 2015. (In Chinese)

[3] W. Zhou, L.B. Hu, H.B. Li, and H.Z. Mo, "Teaching exploration and practice of biochemistry course in food science and engineering specialty,” The Guide of Science \& Education, vol. 10, pp. 90-92, October 2016. (In Chinese)

[4] J. Zhao, "Some thoughts on biochemistry teaching in food science," Science \& Technology Vision, vol.15, pp. 66-67, 2016. (In Chinese)

[5] W.C. Liu, "Application of micro-course and flipping classroom in Biochemistry curriculum teaching," Testing and Evaluation, vol.05, pp. 138, 2017. (In Chinese)

[6] Z.J. Han, D.M. Cheng, and L. Ma, "The teaching of biochemistry experiment reflects the goal of training undergraduate talents - taking food science and engineering as an example," Journal of Higher Education, vol.20, pp. 37-39, 2017. (In Chinese)

[7] L.H. Chen, Z.Y. Xiong, S. Jiang, and Y. Dong, “Teaching reform on the biochemistry type comprehensive design experiment based on food professional characteristics,” Farm Products Processing, vol.07, pp. 8485+88, April 2016. (In Chinese) 